\title{
Uso abusivo de benzodiazepínicos: o processo de desprescrição
} Abusive use of benzodiazepines: the deprescription process

\author{
Charles Maroly Lessa Mantovani ${ }^{1}$ (D), Fábio Franchi Quagliato ${ }^{1}$
}

Os benzodiazepínicos são drogas de ação central que atuam potencializando a atividade inibitória do ácido $\gamma$-aminobutírico (GABA) no sistema nervoso central, tendo como resultado a hipnose e o efeito ansiolítico. $\mathrm{Na}$ atualidade, mais de 20 derivados de benzodiazepínicos já são aprovados internacionalmente, sendo o primeiro introduzido na década de $1960 .^{1}$

O uso dessa medicação é altamente seguro e eficaz a curto prazo, entre duas e quatro semanas. Porém, a utilização além desse período está associada com o desenvolvimento de dependência física e psicológica, sendo esses efeitos mais acentuados em idosos em razão da presença de comorbidades e/ou uso concomitante de outros fármacos. ${ }^{1}$

Na prática, o que vemos são cada vez mais prescrições desses agentes farmacológicos, principalmente em indivíduos idosos, sendo a classe de fármacos de ação central mais prescrita no mundo. Assim, a desprescrição dos benzodiazepínicos é um grande desafio, em razão da alta taxa de dependência e dos sintomas acarretados pela sua retirada.

No Brasil, em um estudo avaliando 3.368 prescrições, foi demonstrada prevalência de $20,6 \%$ de benzodiazepínicos, dado semelhante ao encontrado em países mais desenvolvidos. Porém, em alguns desses países, a venda sem receita médica é permitida, e no Brasil, o consumo só ocorre por meio de uma prescrição. Isso nos alerta sobre um possível desconhecimento dos profissionais de saúde sobre as indicações e os efeitos adversos da medicação ou, até mesmo, da dificuldade na retirada da droga nesses pacientes. ${ }^{2}$

É importante ressaltarmos os efeitos negativos do uso indiscriminado dessa classe medicamentosa. No curto prazo, ocorrem os sintomas conhecidos como efeitos de "rebote", principalmente distúrbios associados ao sono. Além disso, outros problemas podem estar presentes, como letargia, sedação e incapacidade de realização de determinadas atividades diárias, aumentando riscos de acidentes de trânsito e fraturas, sobretudo em idosos. Vale destacar que a maioria desses efeitos colaterais é dose-dependente. Outro ponto a se enfatizar é a consequência a longo prazo desse uso indiscriminado. Diversos estudos têm mostrado o aumento do risco de desenvolver distúrbios cognitivos, como perda de memória, déficit de atenção, alteração de concentração e até mesmo demência., ${ }^{1,3}$

Visto isso, destacamos dois artigos recentemente publicados que abordam condutas frente à dependência desses fármacos e métodos com melhores níveis de evidência para a desprescrição. Um deles, publicado em 2017, mostra que a retirada deve ser gradual, com período variável a depender da dosagem em uso, no intuito de minimizar os efeitos negativos da retirada. $O$ que chama a atenção é o fato de que esses sintomas de retirada são determinados também pela capacidade de o indivíduo tolerá-los, e um período entre quatro e oito semanas é adequado para grande parte deles. Além disso, a maioria dos sintomas observados em estudos foi leve (insônia, ansiedade e inquietação) e de curta duração, raramente ocorrendo sintomas graves como convulsões. ${ }^{1,3}$

Um ponto importante descrito nessas recomendações é o engajamento do paciente nesse processo, o que chamaram também de "psicoeducação". Nessa etapa, eles descrevem a importância de mostrar ao indivíduo que os efeitos da retirada são mínimos e breves, quais as consequências do uso prolongado, as possíveis alternativas e os benefícios dessa descontinuação, entre eles, a melhora da atividade psicomotora e cognitiva.,

Com base no engajamento do paciente, segue-se a retirada da medicação, sempre de forma gradual e lenta, sendo importante a orientação quanto à higiene do sono, ao relaxamento e a outras técnicas descritas, como terapia comportamental, que apresenta bom nível de evidência. Em alguns casos, recomenda-se, para a dificuldade de dormir, durante o processo de retirada, o uso de antidepressivos, anti-histamínicos e melatonina, porém apenas após a tentativa com métodos não farmacológicos. ${ }^{1,3}$

Em pacientes com depressão, ansiedade e outros transtornos mentais graves ou do sono associados, recomenda-se

${ }^{1}$ Centro Universitário Barão de Mauá - Ribeirão Preto (SP), Brasil.

Autor correspondente: Charles Maroly Lessa Mantovani - Centro Universitário Barão de Mauá - Rua Ramos de Azevedo, 423 CEP: 14090-180 - Ribeirão Preto (SP), Brasil - E-mail: charlesmlmantovani@ gmail.com

Recebido em 25/06/2018 - Aceito para publicação em 29/11/2018. 
o controle inicial dessas doenças antes de tentar a retirada dos benzodiazepínicos, visto que o processo pode ser mais difícil e angustiante. Sugere-se, nesse tipo de paciente, considerar o auxílio de algum especialista. Além disso, em indivíduos mais idosos e com uso crônico, a retirada também pode ser mais complexa, tendo como estratégia apenas a redução da dose..$^{1,3}$

Assim, essas recomendações são importantes na prática do profissional de saúde atualmente, visto as altas taxas de uso e os efeitos negativos dessas drogas, bem como os diversos benefícios para o paciente com a desprescrição.

\section{REFERÊNCIAS}

1. Soyka M. Treatment of benzodiazepine dependence. N Engl J Med. 2017;376(12):1147-57. doi: http://doi. org/10.1056/NEJMra1611832

2. World Benzodiazepine Awareness Day. Educating communities on dangers of prescribed benzodiazepines [Internet]. 2018 [acessado em 8 jun. 2018]. Disponível em: http://w-bad.org/.

3. Pottie K, Thompson W, Davies S, Grenier J, Sadowski CA, Welch V, et al. Deprescribing benzodiazepine receptor agonists. Can Fam Physician. 2018;64(5):339-51. 